\title{
Analysis of Resource Ownership of Small Medium Industry and Their Effect on Natural Disaster Preparedness in the Beach Area (Study on SMEs Food Industry Branch)
}

\author{
Mohamad Adfar ${ }^{1 *}$, Patta Tope ${ }^{2}$, Muchtar Lutfi ${ }^{3}$ \\ ${ }^{1}$ Student of Doctoral Program in Economics, Tadulako University, \\ ${ }^{2,3}$ Department of Economics and Development Studies, Faculty of Economics and Business, Tadulako University \\ *Correspondent Author
}

\begin{abstract}
Palu Bay is one of the bays in a seismically active area in Indonesia which is traversed by the Palu-Koro fault segment. In the aftermath of a major natural disaster in the Region on September 28, 2018 Palu City, Donggala Regency and Sigi Regency were areas that were most affected by this disaster, so it was necessary to identify the level of community preparedness, especially for SMEs in dealing with natural disasters in the future and how the impact of resource ownership will be that they have whether the resource significantly affects SMEs preparedness to face natural disasters. This research was conducted three years after the natural disaster in the Palu Bay Area. The assessment was carried out through a questionnaire involving 260 SMIs that were chosen randomly and from the four variables of SMEs resources studied, that the resources that had an effect on disaster preparedness were the capital variable, which was 0.07 , the entrepreneurial variable was 0.35 , the labor variable was $\mathbf{- 0 . 0 3}$, and the Information Technology variable is not significant. While the level of preparedness of SMEs in dealing with natural disasters in the future, $17.31 \%$ of respondents are stated to be "not ready", $60.90 \%$ "somewhat ready" and $23.8 \%$ "ready" while none of the respondents were "very prepared". This lack of readiness of SMEs clearly requires the attention of all stakeholders in fostering the resilience of SMEs.
\end{abstract}

Keywords: SMEs, Disaster, Economics, Industry

\section{INTRODUCTION}

A $\mathrm{n}$ earthquake event occurred in Palu on 28 September 2018 and was followed by a series of tsunami waves that destroyed the Palu Bay Area, that the 7.5 Mw Palu Earthquake occurred at sunset on 28 September 2018 at 18 $: 02: 44$ local time (10:02:44 UTC), with the epicenter located at $0.18^{\circ}$ South Latitude and $119.85^{\circ}$ East Longitude, $\sim 80 \mathrm{~km}$ north of Palu City in Central Sulawesi, Indonesia (Han et al., 2021; Zhao, 2021). While the aftershocks (28 September to 22 November 2018) were mostly located southeast of the mainshock thus showing a northwest-southeast trend with a total length of about $200 \mathrm{~km}$ and consistent with the nodal plane dipping to the east of the gCMT solution.
Several studies have discussed the cessation of post-disaster business activities and the factors that led to the cessation of business are also not well understood so that in order to rebuild the economy after a natural disaster it is necessary to identify the level of preparedness of MSMEs or SMES in dealing with natural disasters and how the impact of the existence of natural resources is needed. What resources do they have whether these resources affect MSMEs or SMEs in preparing themselves for natural disasters (Badoc-Gonzales et al., 2021; Hossain et al., 2022).

There are several studies that have been conducted previously that identify preparedness in dealing with disasters. This disaster research refers to events that have the potential to cause harm to individuals, organizations, communities, or the environment (Hasan et al., 2021; Shah et al., 2019). When natural disasters such as hurricanes and tornadoes occur, of course, the survival of the organization will be threatened, organizations cannot control the physical characteristics of natural disasters such as intensity and frequency, but organizations can minimize the potential impact of disasters by adopting hazard adjustments (J.M., 1996).

As it is known that SMEs have resources or inputs in producing goods output (Chaudhuri et al., 2022). The existence of resources or what can be called factors of production are capital, labor, entrepreneurship and the use of information technology which is sometimes not understood as an asset related to preparedness actions in dealing with disasters, so the author deserves to analyze it. By understanding that the resource variable will play a role in the preparedness of the SMES, it can certainly be a concern for the SMES management in providing special treatment in terms of increasing the resource variable (Karunarathne and Gress, 2022). This will also make it easier for the Government to take pre-disaster management policies for organizations, especially Small and Medium-scale Industries, by combining increased productive economic efforts with increased preparedness in an integrated and sustainable manner (Cooper et al., 2021; Roberts et al., 2021). 


\section{METHOD}

This research is a survey research conducted on Small and Medium Industries (SMEs) with a branch of the food industry in Central Sulawesi, especially SMEs located in the Palu Bay Area and other affected areas (Estensoro et al., 2021; Zide and Jokonya, 2022). This research is quantitative and uses data in the form of numbers in statistical analysis. Therefore, the data collected is cross sectional (Walker et al., 2014). The population in this study is Small and Medium Industries (SMEs) located in Palu City, Donggala Regency and Sigi Regency with the business criteria being a branch of the food industry that is still active, whether affected by natural disasters or not. The population is 745 businesses/person with a sample of 260 SMEs.

\section{DATA ANALYSIS}

Data analysis was carried out through three stages, namely:

1. Descriptive analysis to obtain a count of the number of responses associated with different values of each variable (De Simone et al., 2022). The relative occurrence or frequency of different values of a variable expressed in numbers or percentages.

2. Measuring the level of preparedness of SMEs in dealing with natural disasters (adopting the research of Temitope Egbelakin et al. 2018), namely the level of preparedness is grouped into four predetermined score intervals as follows 0-5 (less ready), 6-10 (somewhat ready), 11-16 (ready), and 17-21 (very ready) which are response variables with 21 questions as preparedness measures, each item in the list of readiness measures is associated with a dummy variable which is coded 1 if the action is adopted by SMEs and 0 if no.

3. Path analysis to analyze the pattern of relationships between variables with the aim of knowing the direct or indirect effect of a set of independent (exogenous) variables on the dependent (endogenous) variables (Liu et al., 2022; Park et al., 2021).

\section{RESULTS AND DISCUSSION}

\section{Preparedness of Small and Medium Industries in the Palu Bay Area.}

Descriptive statistical analysis was conducted to explore the preparedness actions that have been carried out by SMEs in the aftermath of a natural disaster in the Palu Bay area, namely Sigi Regency, Donggala Regency and Palu City. This analysis will see a comparison of the actions taken through each SMEs resulting in four categories, namely 1). Improving Knowledge, 2).Continuous Insurance and Business Planning, 3). Actions to Maintain Business Continuity and 4). Damage Mitigation Measures. Calculate the average value of the responses from the twenty-one preparedness actions that are part of the four categories above. The results of the comparison of preparedness with twenty-one measures in the three survey areas are summarized in the figure below:

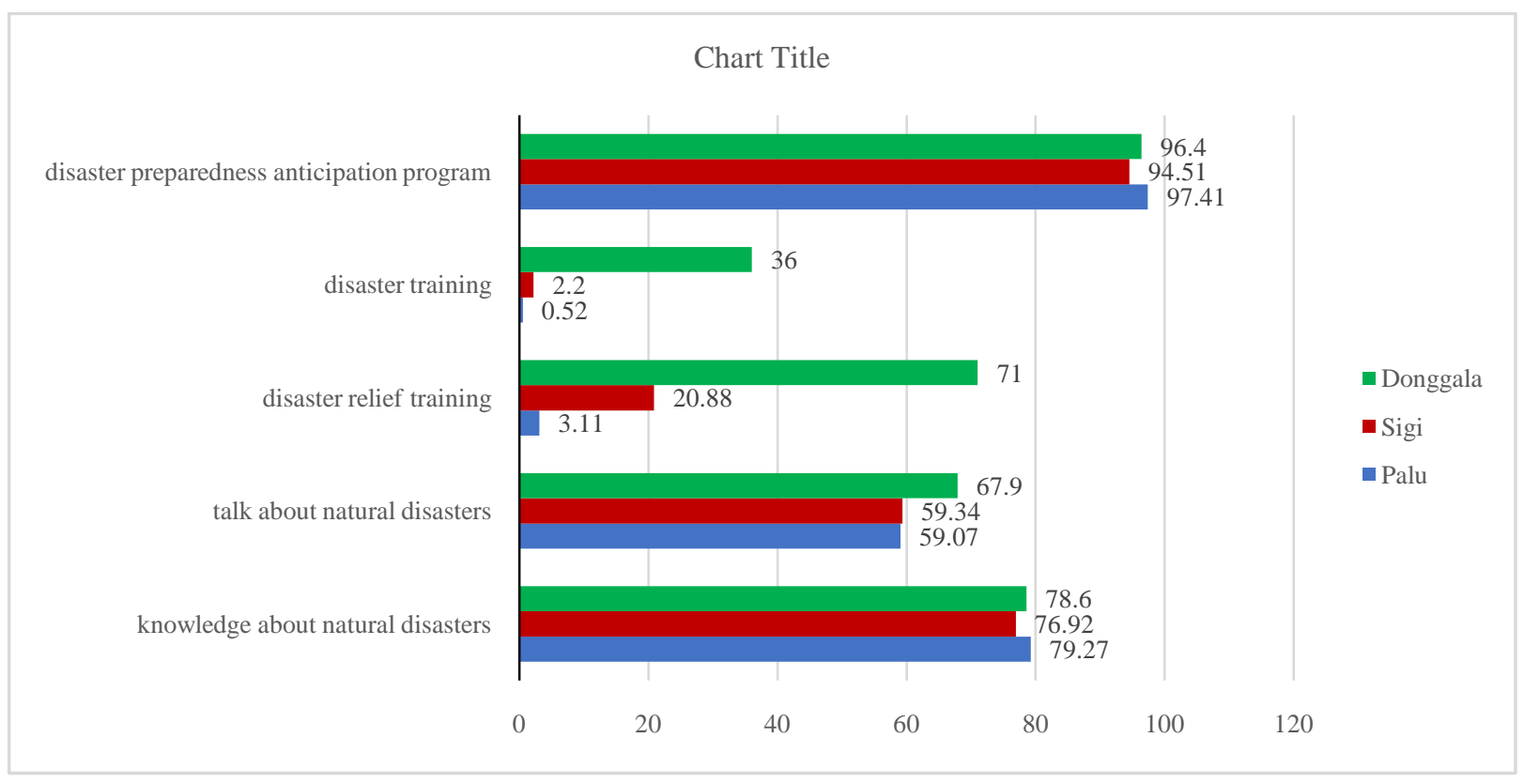

Figure 1: Activities to increase Knowledge

As shown in the picture above, the majority of respondents in these three areas have read Knowledge about natural disasters, namely $79.27 \%$ of respondents in Palu City, $76.92 \%$ of respondents in Sigi, $78.60 \%$ of respondents in Donggala.
While $59.07 \%$ of respondents in Palu City, $59.34 \%$ of respondents in Sigi and $67.90 \%$ of respondents in Donggala has also discussed and shared with employees about natural disasters. There was a significant difference, namely in 
respondents who had attended first aid courses on natural disasters where only $3.11 \%$ of respondents in Palu City took first aid courses, $20.88 \%$ of respondents in Sigi, $71 \%$ of respondents in Donggala. The lowest adoption rate in this category includes providing support for other disasters related to disaster training programs for employees with only $0.52 \%$ of respondents in Palu City, 2.20\% of respondents in Sigi and $36 \%$ of respondents in Donggala. Then, for respondents who support the disaster preparedness anticipation program for employees in these three areas, it is very high $(97.41 \%$ in Palu City, $94.51 \%$ in Donggala, and $96.40 \%$ in Donggala).

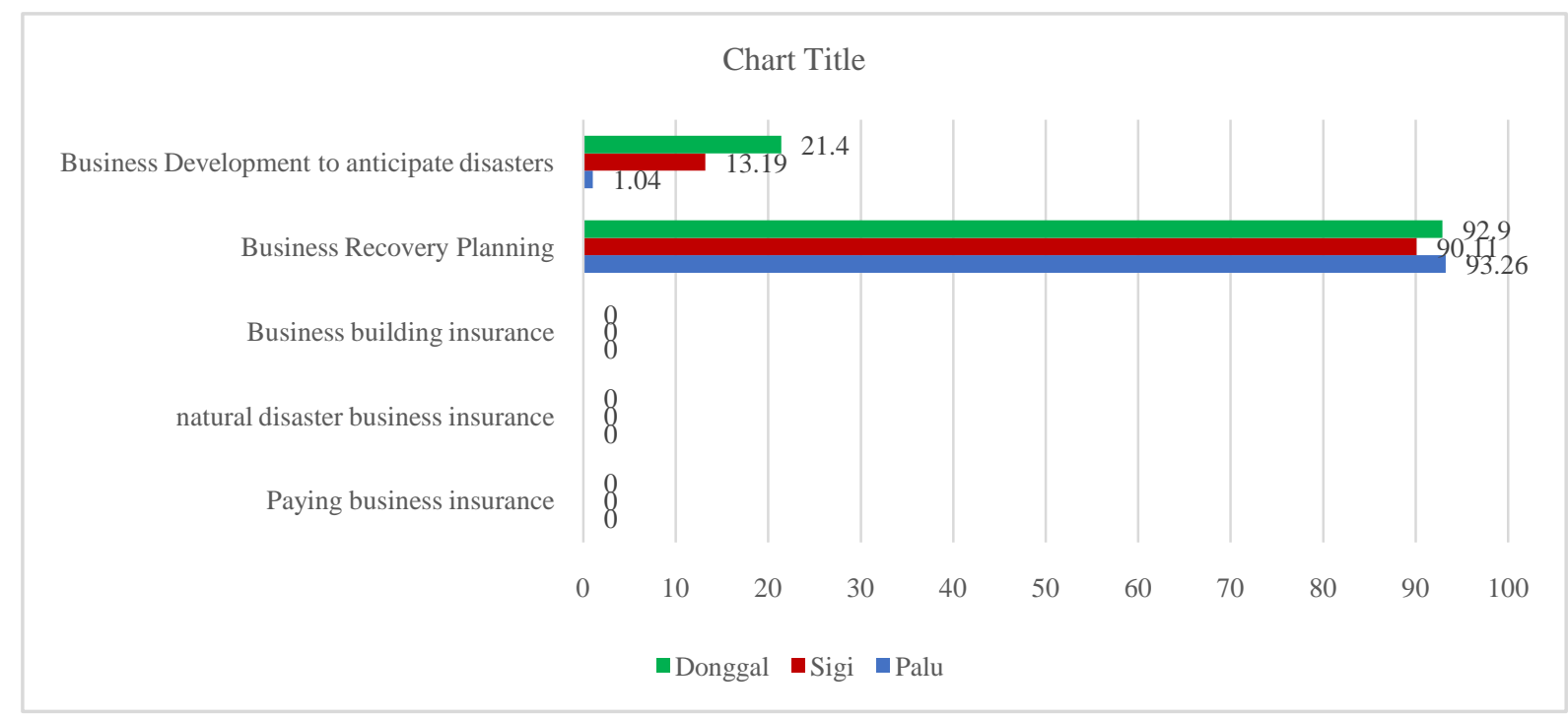

Figure 2: Sustainable Insurance and Business Planning.

In the second category of this preparedness action, it was identified that there were no SMIs that bought insurance, either certain insurance for their business, or insurance packages as a whole or insuring the building where their business was located. If you look at the respondents' responses to the payment of the insurance package, that in Palu City, Kab. Sigi and Kab. Donggala has a $0 \%$ response, meaning that none of the respondents bought an insurance package to prepare businesses for natural disasters. However, it is different when respondents are asked the question "Will they plan to restore their business in the event of a natural disaster", most of the respondents gave a lot of attention to this planning, namely $93.26 \%$ of respondents in Palu City, $90.11 \%$ of respondents in Sigi District and 92, 90\% of Respondents in Kab. Donggala. Meanwhile, whether respondents will develop a business plan to anticipate natural disasters, it is still low, namely at $1.04 \%$ in Palu City, $13.19 \%$ in Kab. Sigi and $21.40 \%$ in Donggala Regency.

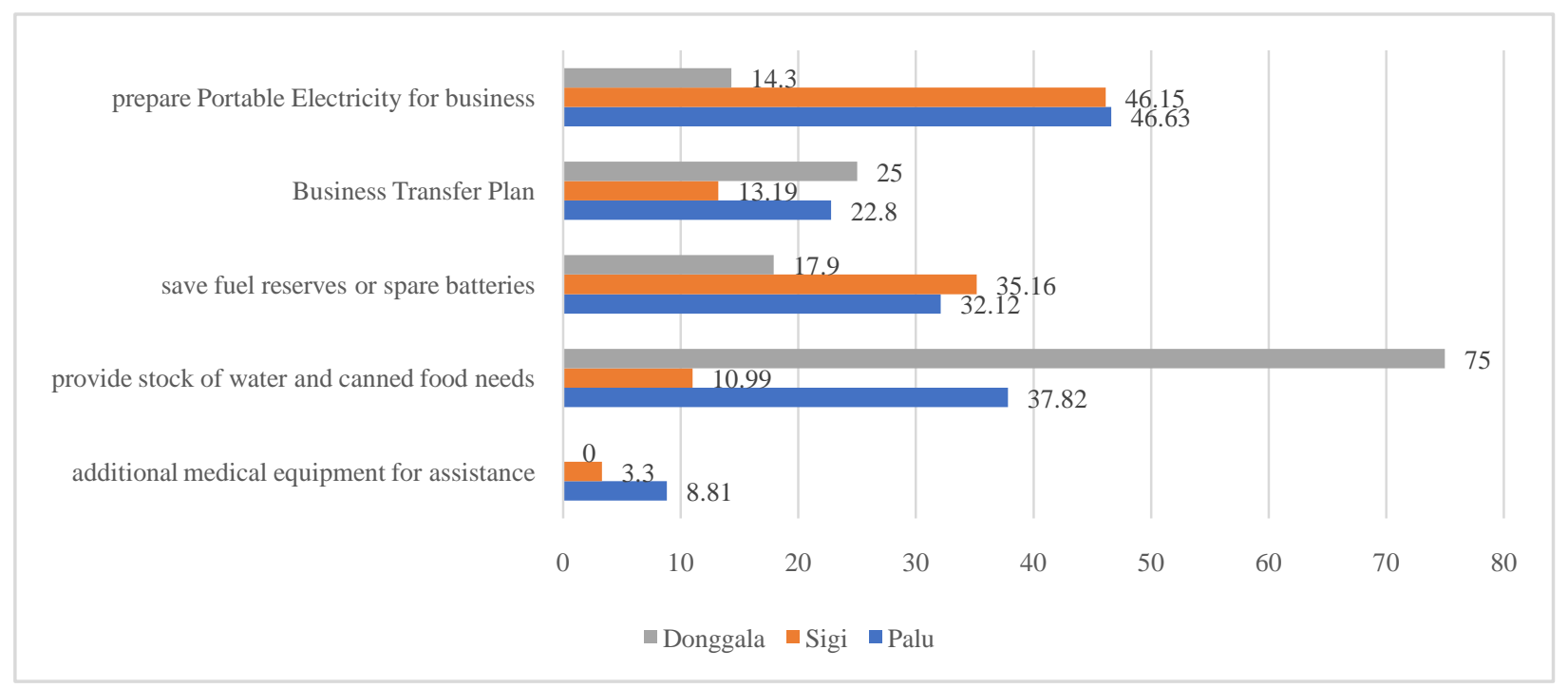

Figure 3: Business Survival Measures 
In the third category as in the graph above, Continuity Actions and maintaining business continuity, 8.81\% SMESin Palu City and 3.30\% SMEs in Kab. Sigi has a first aid kit or medical supplies. However, none of the SMESrespondents in Donggala Regency have a first aid kit. Meanwhile, SMEs anticipates by providing stock of water and canned food in Palu City as much as $37.82 \%$, in Kab. Sigi as much as $10.99 \%$ and in Kab. Donggala as much as $75 \%$. Regarding the supply of fuel and electricity, respondents in the three regions are still lacking in storing fuel reserves or backup batteries, namely only $32.12 \%$ of respondents in Palu City, $35.16 \%$ of respondents in Kab. Sigi, and $17.19 \%$ of respondents in Kab. Donggala. Meanwhile, 50 percent of those who prepare generators at their place of business in case of power failure also do not reach $50 \%$ in the three areas $(46.63 \%$ in Palu, $46.15 \%$ in Sigi, $14.30 \%$ in Donggala). And the desire to plan to move to a certain place in the event of a natural disaster is also still low in these three areas, namely only $22.80 \%$ of respondents in Palu City, 13.19\% of respondents in Sigi Regency and $25 \%$ of respondents in Kab. Donggala.

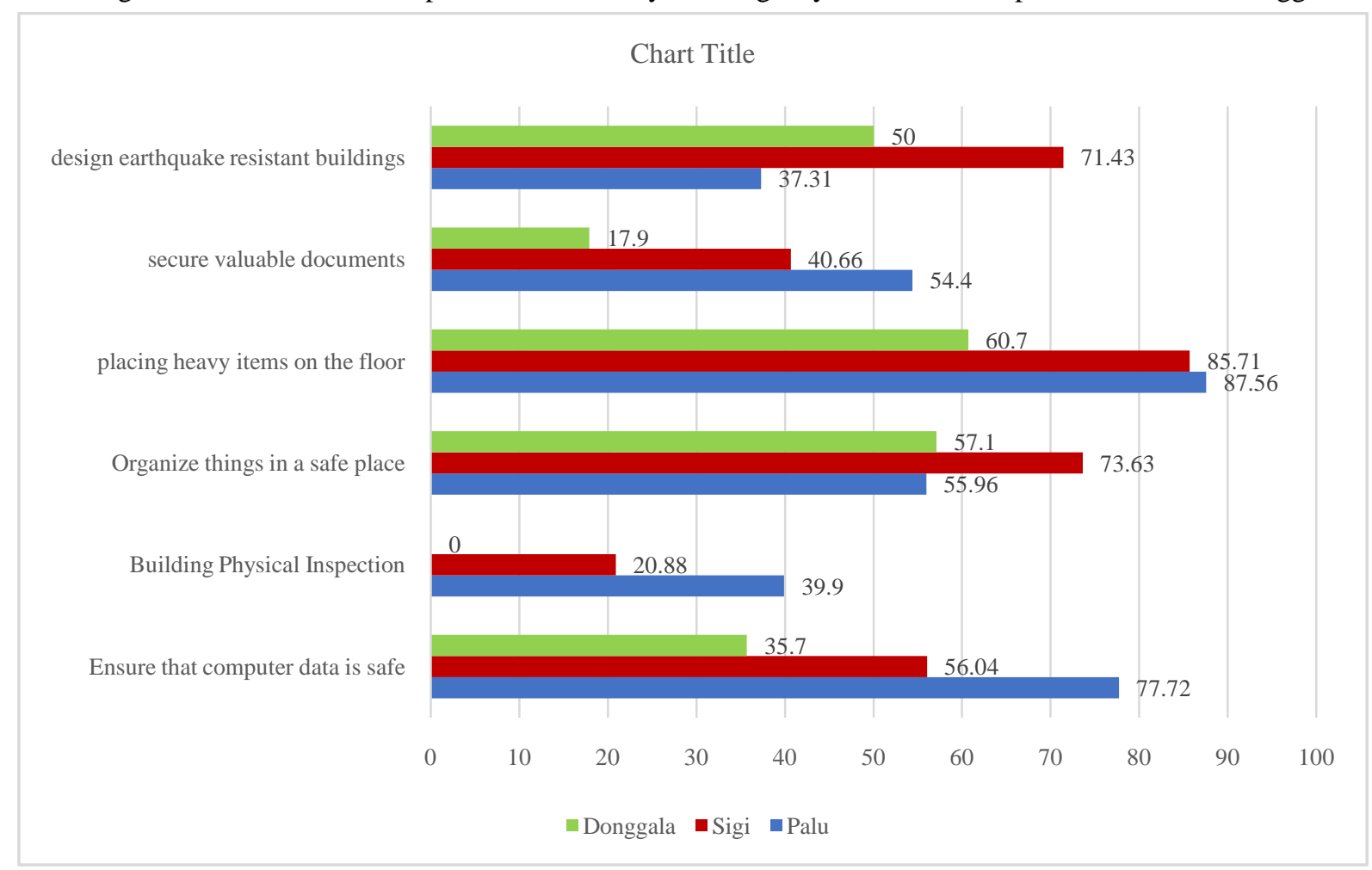

Figure 4: Damage Mitigation Measures

In the fourth category, namely Damage Mitigation Actions by means of respondents placing heavy objects on the floor, the highest level of adoption is $87.56 \%$ in Palu City, $85.71 \%$ in Kab. Sigi while in Kab. Donggala is $60.70 \%$. The low cost and ease of adoption of these mitigation measures could be attributed to their adoption rate. In this damage mitigation action, the lowest value is also seen in inviting a technician or builder to carry out a systematic assessment of the physical business building, namely for Palu City 39.90\%, Kab. Sigi $20.88 \%$ while in Kab. Donggala has not adopted this preparedness.

Then the next damage mitigation action is to ensure that computer data or important data is safe enough in the event of a disaster. This action is quite different in the three regions, namely $77.72 \%$ in Palu City, 56.04\% in Kab. Sigi, 36.70\% in Kab. Donggala. Meanwhile, those who strengthen shelves and place objects at the top to make them safe when a disaster occurs, the SMESin the three regions has achieved more than $50 \%$, namely $55.96 \%$ in Palu City, $73.63 \%$ in Kab. Sigi, and
$57.10 \%$ in Kab. Donggala. Furthermore, based on respondents in the three regions, $54.40 \%$ in Palu City, $40.66 \%$ in Sigi Regency and $17.90 \%$ in Kab. Donggala has secured records or receipts for purchasing raw materials. The last preparedness action was that SMEs designed buildings to be more durable/safe in the event of a natural disaster. This action was adopted by SMES s in three areas, namely $37.31 \%$ in Palu City, $71.43 \%$ in Kab. Sigi and 50\% in Kab. Donggala.

The four responses were combined to see the total number of preparedness actions taken by respondents. The results are summarized in Figure 5. Responses were grouped into four score intervals defined as 0-5 (poorly prepared), 6-10 (somewhat ready), 11-16 (ready), and 17-21 (very ready). As illustrated in the figure below, the percentage of respondents in the unprepared group that has adopted up to five mitigation measures is $17.31 \%$. Then the number of groups of respondents who adopt up to ten mitigation measures is 60.90 $\%$ and this group is the most numerous. Meanwhile, the number of groups that adopted mitigation measures was up to 
16 , amounting to $21.79 \% \%$ and it turned out that there was no group that was very ready to face natural disasters $(0 \%$ value). 16 actions.

From the results of the calculation of responses that have been grouped into four score intervals, as many as 60.90 respondents in the three areas that became the object of the study were declared "somewhat ready" to face disasters, $17.31 \%$ "less ready" and $21.79 \%$ "ready" while none of the respondents were "very prepared" for natural disasters. The level of natural disaster preparedness for SMEs in the Palu Bay area can be seen in Figure 5.

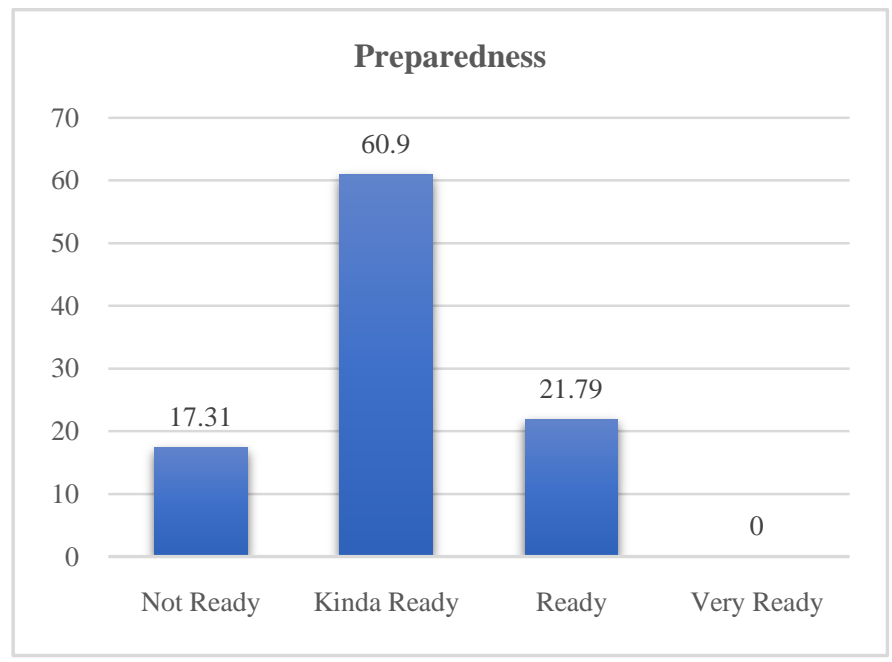

Figure 4: Disaster Preparedness Level

\section{Path Equation Model test}

Endogenous Variable Normality Test.

The normality test of endogenous variables can be seen through the normal probability plot curve forming a linear pattern between the residual and the expected value. If the scattering of points forms or approaches a linear line, the assumption of normality is met (Qu et al., 2021). From the processing results obtained a plot curve as shown in Figure 6.

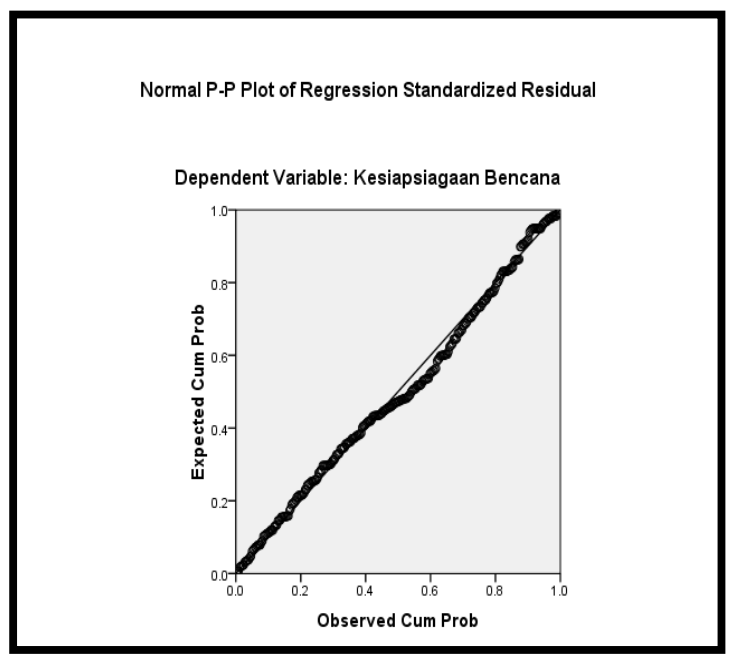

Figure 6. Endogenous Variable Normality Test result curve

Based on the curve, it was found that the point emission approached a linear line, so it can be said that the assumption of normality in this study has been fulfilled. The next step in path analysis is testing the fit of the model.

\section{Model Fit Test}

The results of processing using Lisrel version 8.7 produce the output of several model fit tests. The proposed model or the default model is formed in the following structural equation:

$$
\begin{aligned}
& \mathrm{X} 2=\gamma 1 \times 1+\gamma 3 \times 3+\gamma 4 \times 4+e \\
& Y=\rho 1 \times 1+\rho 2 \times 2+\rho 3 \times 3+\rho 4 \times 4+e
\end{aligned}
$$

The model fit test obtained the results as shown in the table below.

Table 1. Model Fit Test

\begin{tabular}{|c|c|c|}
\hline Test & Result & Conclusion \\
\hline Chi Square & 0,00 & $\begin{array}{c}\mathrm{H}_{0} \text { is rejected, minimum } \\
\text { result }\end{array}$ \\
\hline Degree of Freedom & 0 & Perfect Fit \\
\hline P-value & 1,00000 & Perfect Fit \\
\hline RMSEA & 0,000 & Perfect Fit \\
\hline
\end{tabular}

According to (Sitinjak, 2006), the chi-square, degree of freedom, $p$-value, and RMSEA values indicate that the model is in accordance with the data or can be said to be a fit model. From the results of the following Lisrel program output, it also shows that the model used already has a perfect fit (saturated model) or it can be said that the model has the highest level of fit. This causes the incremental fit test (NFI, IFI and CFI) and parsimony fit test (AIC) to be unnecessary. The next step after knowing the model fit is to find the path coefficients of each path in the model, then test the significance of each path coefficient.

\section{Path Coefficient Significance}

The model that is formed in the path equation will bring up the path coefficients whose significance needs to be tested next. The significance of the existing path coefficients will affect the path significance of the path diagram of the resulting model (Kumar et al., 2020). The significance test using the t-student test with the null hypothesis is that there is no significant effect of exogenous variables on endogenous variables. The expected decision of this test is to reject the null hypothesis, which means that there is a significant influence between exogenous variables on endogenous variables. The figure below shows a path diagram of the results of the LISREL 8.70 program processing which displays the estimated values of significant and insignificant path coefficients based on the t-values, as follows: 


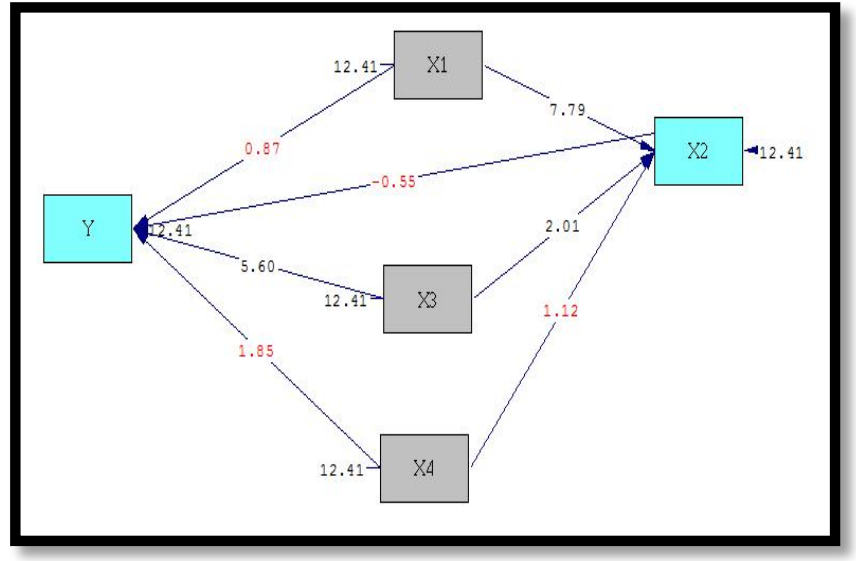

Figure 7. Significance Path Diagram

The path diagram in the image above still contains an insignificant path, namely the red coefficient value, because the t-test value is smaller than 1.96. The path is the variables of SMEs capital (X1), labor (X2) and information technology (X4) on disaster preparedness (Y) if it is seen as a direct influence. The entrepreneurial variable has a direct significant effect on disaster preparedness. Meanwhile, SMES capital (X1) and entrepreneurship (X3) have a direct significant effect on the workforce (X2) and an indirect effect on disaster preparedness if through the labor variable (X2). Meanwhile, the information technology variable has no direct or indirect effect either through the labor variable or directly on disaster preparedness. Therefore, data processing is continued by using the trimming model, namely by reprocessing it without including insignificant paths.

\section{trimming model}

Variables that are not significant through direct or indirect influence are information technology variables (X4) so that the proposed trimming model does not include information technology variables (X4). Based on the results of further processing of the trimming model, a path diagram of the tvalues is obtained as shown in Figure 8.

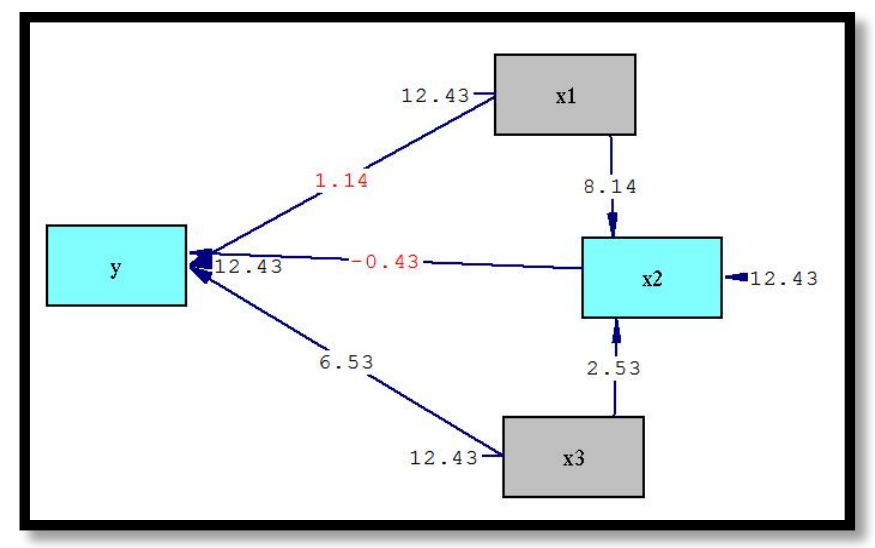

Figure 8. T-Values Significance Path Diagram of the Trimming Model.

The path is SMEs capital (X1), labor (X2) and entrepreneurship (X3) on disaster preparedness (Y) both in terms of direct and indirect effects. The trimming model illustrates that SMEs capital (X1) does not directly affect disaster preparedness (Y) but its effect is still significant if it is through the labor variable (X2). And the labor variable (X2) does not significantly affect disaster preparedness (Y) singly but must be accompanied by the SMEs capital variable (X1) and entrepreneurship (X3). Meanwhile, entrepreneurship can be said to significantly affect disaster preparedness (Y) either directly or indirectly. Based on this model, a model with estimated path coefficients can be seen in Figure 9.

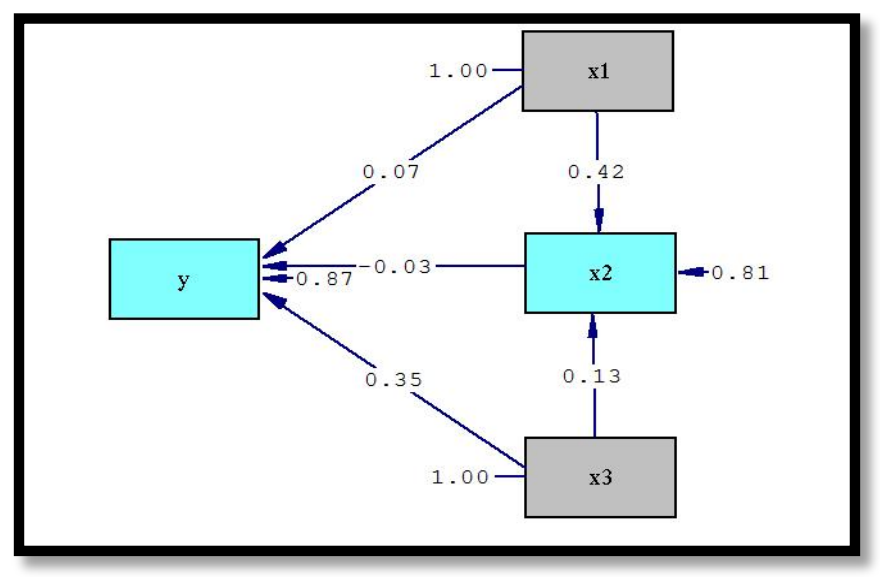

Figure 9. Coefficient Estimation Value Path Diagram

$$
\begin{aligned}
& \mathrm{X}_{2} \quad=0.42 * \mathrm{X}_{1}+0.13 * \mathrm{X}_{3}, \mathrm{R}^{2}=0.19 \quad \text { Model (1) } \\
& \mathrm{Y}=-0.025 * \mathrm{X}_{2}+0.067 * \mathrm{X}_{1}+0.35 * \mathrm{X}_{3}, \mathrm{R}^{2}=0.13 \operatorname{Model}(2)
\end{aligned}
$$

Based on the path equation above, none of the path coefficients is close to 1 , so it can be said that the estimation results are not offending estimates or estimated values that exceed the acceptable limits (Wijanto, 2008). Through the path equations, it can also be seen that the coefficient of determination in each equation is not too high, namely 19 percent and 13 percent. This is not a problem in path analysis because according to Goldberger in Wijanto (2008) there is no rule in the classical regression model that requires that $\mathrm{R} 2$ or the coefficient of determination must be high. While path analysis is also a development of the classical regression model. The value of the coefficient of determination for each of the above equations is as follows:

1. Equation (1) variable labor has a coefficient of determination of 19 percent. This means that the SMEs and entrepreneurship capital variables contribute to the increase or decrease in the workforce by 19 percent. The rest comes from the contribution of other variables outside the model. SMI and entrepreneurial capital variables contribute positively to the increase in the size of the workforce. It can be said that any increase in the SMEs and entrepreneurship capital variables will also have an impact on the increase in the labor variable.

2. Equation (2) disaster preparedness variable has a coefficient of determination of 13 percent. This 
means that the variables of SMEs capital, labor and entrepreneurship contribute to the increase or decrease in the percentage by 13 percent. The rest comes from the contribution of other variables outside the model. The contribution given by the SMEs and entrepreneurship capital variables is positive, meaning that any increase in the SMEs and entrepreneurship capital variables will have an impact on an increase in the disaster preparedness variable. Meanwhile, the labor variable has a negative contribution to disaster preparedness, meaning that any increase in the labor variable will actually decrease disaster preparedness for SMIs.

In this section, a detailed discussion of the variables that affect the Preparedness of Small and Medium Industries is presented in the Palu Bay Area. Typical estimators in path analysis are related to direct and indirect effects between exogenous and endogenous variables. To be able to see the influence in general, it is presented in the following table:

\begin{tabular}{|c|c|c|c|c|}
\hline No & Variable & $\begin{array}{c}\text { Direct } \\
\text { variable }\end{array}$ & $\begin{array}{c}\text { Indirect variable } \\
\text { with X2 }\end{array}$ & Total \\
\hline 1 & $\mathrm{X}_{1} \rightarrow \mathrm{X}_{2}$ & 0,42 & - & 0,42 \\
\hline 2 & $\mathrm{X}_{3} \rightarrow \mathrm{X}_{2}$ & 0,13 & - & 0,13 \\
\hline 3 & $\mathrm{X}_{1} \rightarrow \mathrm{Y}$ & 0,07 & $-0,01$ & 0,06 \\
\hline 4 & $\mathrm{X}_{2} \rightarrow \mathrm{Y}$ & $-0,03$ & - & $-0,03$ \\
\hline 5 & $\mathrm{X}_{3} \rightarrow \mathrm{Y}$ & 0,34 & 0,01 & 0,35 \\
\hline
\end{tabular}

Based on the table above, it can be interpreted the path analysis model and the influence of each variable in a more detailed discussion as follows:

\section{The Effect of SMEs Capital Resources on Natural Disaster Preparedness}

The direct influence of these resources on disaster preparedness is higher than the indirect effect through the labor variable. The direct influence of SMES capital on disaster preparedness is 0.07 . This shows that every increase in the variable capital resources of SMEs will also increase the level of preparedness for natural disasters directly. The results of this study are in accordance with research conducted by Aydin, (2014) which examines the factors that influence the preparedness of Small and Medium Enterprises and Technoparks in dealing with disasters in Turkey that the company's financial condition has a significant effect on disaster preparedness, especially companies that use capital accumulation. themselves as a source of initial capital are better prepared to face disasters.

In this study, capital is the initial investment in the establishment of a business (fixed cost) including the value of land, buildings, machinery, equipment, facilities and infrastructure including capital accumulation, excluding working capital used to carry out industrial activities (variable cost). Capital restrictions in regulations with SMEs criteria, do not make it a barrier to the effect of this capital on the preparedness of SMEs in the face of natural disasters. It is known that the criteria for small industries are those that employ a maximum of 19 (nineteen) workers and have an investment value of less than Rp. 1,000,000,000.00 (one billion rupiah) excluding land and buildings for business premises, while the Medium Industry employs a maximum of 19 (nineteen) workers and has an investment value of at least Rp. 1,000,000,000.00 (one billion rupiah); or employs at least 20 (twenty) workers and has an investment value of at most Rp. 15,000,000,000.00 (fifteen billion rupiah) as stipulated in the Regulation of the Minister of Industry of the Republic of Indonesia Number 64/M-Ind/Per/7/2016.

The influence of a positive relationship between capital and preparedness can be understood the more capital owned by the SMEs will increase the preparedness of the SMEs, meaning that a lot of capital will open up opportunities to pay attention and prepare SMEs in dealing with disasters such as inviting builders or construction experts to measure the level of physical strength of the building where it is located. business, renovating and strengthening the structure of business premises, providing education and guidance to workers on disaster preparedness, purchasing standard cabinets or strengthening shelves for business premises, preparing for everything related to natural disasters.

\section{The Influence of SMEs Manpower Resources on Natural Disaster Preparedness}

The influence of the SMEs workforce variable on natural disaster preparedness is -0.03 . This shows that every increase in the SMEs workforce variable will actually reduce the level of natural disaster preparedness. In addition, the SMEs workforce variable also acts as an intermediate variable in influencing the indirect effect of the SMEs capital resource variable and the entrepreneurial variable.

The negative influence between the workforce variable and the disaster preparedness variable on SMES is not in line with the findings of a study conducted by Drabek in Dahlhamer \& D'souza, (1995) which measured two types of tourism company samples and found that organizational size was significantly related to planning. disaster evacuation. In the study analyzing 65 companies, Drabek noted that "the more employees the company has, the wider the disaster evacuation planning"' and company size is a very significant predictor variable of disaster in evacuation planning (Drabek in Dahlhamer \& D'souza, 1995). The same study was conducted by Aydin, (2014) that organizations that have a larger size in terms of the number of employees have a higher disaster preparedness score.

The difference in the results of this study is understandable, considering that there are differences in the characteristics of SMEs in Indonesia with the limitation on the number of workers as stipulated in the Regulation of the Minister of Industry of the Republic of Indonesia Number 64/MInd/Per/7/2016. Small Businesses studied by previous researchers certainly have good resource qualifications, when 
compared to workers in Indonesia according to the Human Development Index (HDI) report 2011 in Lupikawaty, (2013) that "Indonesia's position is ranked 124 in the Medium Human Development category with the average point is 0.617 . (HDI report 2011). According to the report, the world is divided into 4 categories, namely very high, high, medium and low human development".

If viewed from the data, it can be understood that the characteristics of labor resources studied by previous researchers describe the tendency for their quality to be better than the resources studied in this study, of course, this has an impact on differences in results where the quality of labor resources in previous studies, namely in Europe, has a better index. can reliably contribute to natural disaster preparedness in their companies. With the quality of their workforce resources, they will contribute, for example providing input to management on how small businesses or companies should provide a sense of security to workers by strengthening building structures, preparing for mobilization for workers, workers can encourage disaster mitigation efforts in the work environment. With the communication skills of the workers, they can suggest that the company provides disaster mitigation facilities for each worker who will be in their respective complex or residence.

The condition of small businesses in Indonesia with the quality of their workforce is certainly very contradictory, this can be seen from the data from this study that the education level of business owners (SMEs) mostly has a high school level education (in Sigi Regency 83.5\%, Donggala Regency $57.57 \%$ and Palu City $49.22 \%$ ) of course the limited level of education of SMES owners/entrepreneurs, also has an impact on the selection or recruitment of workers and of course the recruitment of workers, the quality is also not better than the owner. This is understandable considering that most of the small industries have a manual production system. The lack of small industries that adopt modern technology will have an impact on the recruitment of quality workers and in the end, formally educated workers are not needed (Sulteng, 2019). With limited human resources, the workforce is not a positive thing for SMEs in natural disaster preparedness, but a negative burden because there are no ideas that can be expected input from kindergartens for SMEs in preparing for natural disasters, in contrast to industries that have quality and quantity. A high TK will certainly make a good contribution to the company as in the results of previous studies, so the results of this study which found that the TK variable had a significant but negative effect were appropriate.

Influence of SME Entrepreneurship Resources on Natural Disaster Preparedness

Entrepreneurship factor is an ability that exists within a person in using and managing existing production factors so as to be able to produce the expected results. Entrepreneurship is the ability of Planning (Planning), Organizing (Organizing), Movement (Actuating), Supervision (Controling). In SMESorganizations, business owners absolutely have a good entrepreneurial instinct which is certainly a determining factor in the success of running their business.

The results of the observations found that the management of SMEs mostly carried out managerial efforts, including having done business planning, had arranged for employees to carry out tasks according to the work assigned, owners of SMEs often motivated employees to be enthusiastic in doing tasks according to the work assigned. Besides that, SMEs owners also often communicate tasks to their employees in terms of carrying out work, such as how to properly process food according to the stages and so on. No less important is the concern of SMEs owners is to supervise the course of the business (production process) including quality control in maintaining the quality and hygiene of the processed products.

The managerial ability possessed by SMEs is a determining factor in their preparedness to face disasters and if intervention is carried out on this variable, it will certainly affect their preparedness in dealing with natural disasters. It is known that the results of this study found that the entrepreneurial resource variables of SMEs affect the preparedness of natural disasters either directly or indirectly. The direct effect of entrepreneurial resource variables on disaster preparedness is 0.35 . This value is positive, which means that every increase in the entrepreneurial variable will also have an impact on increasing the level of natural disaster preparedness in SMEs. In addition, when compared to two other significant variables that directly affect disaster preparedness, the direct influence of the entrepreneurial variable is the largest, so if you want to improve disaster preparedness in SMEs, this is the variable that needs attention, namely by conducting trainings to improve quality. managerial roles in SMEs, both related to business management and disaster management.

The Influence of Information Technology Resources for SMEs on Natural Disaster Preparedness

Adiningsih, (2003) states that a production function relates inputs to outputs. The function determines the maximum possible output that can be produced with a given number of inputs, or vice versa, the minimum quantity of inputs required to produce a given level of output. The production function is determined by the available technology, capital, labor, materials, etc.

Analyzing the influence of Information Technology in this study is how the use of computer facilities and smart phones in the production process in SMEs. The choice of this technology to be the focus of the analysis is based on the consideration that the use of this technology has become part of business management and some business actors also have it. The answers to the questions asked related to the use of information technology for business actors are 1). that the business actor has a computer or smart phone device, but it is not used to process business data in the product processing process; 2) Business actors have a computer or smart phone but are not used to process business data in making financial 
reports; 3) Some business actors have computers or smart phones that are only used to market products and look for raw materials.

The low utilization of information technology by business actors is understandable, considering that it is understandable given the limited human resources they have, because the use of this technology is closely related to the ability to operate, including making it an opportunity to increase production and take advantage of opportunities to access markets. Indeed, the competitiveness of SMEs can be realized, one of which is the use of Information Technology (IT) to improve business transformation, the accuracy and efficiency of information exchange, expand marketing networks and expand market share. Increasing the competitiveness of SMEs is very necessary in order to be able to survive and compete in the global trade arena, but the condition of the lack of human resources, especially the SMEs branch of the food industry in the study area, is an obstacle in making it happen.

The low level of business actors in utilizing information technology also makes this resource variable insignificant in influencing natural disaster preparedness either directly or indirectly through the SMEs workforce variable, so that the magnitude of the influence on the model cannot be calculated and the statement of the production function uses the information technology variable as a variable. linking inputs with outputs cannot be applied to this model.

\section{Effect of Simultaneous SMEs Resources on Natural Disaster Preparedness}

The simultaneous influence of SMEs resources on natural disaster preparedness shows the total direct influence between the variables of SMEs capital resources, SMEs workforce resources and entrepreneurship on natural disaster preparedness. Based on table 4.4, it is found that the number of direct effects simultaneously is 0.38 . This shows that simultaneously significant SMEs resources will have a positive effect on increasing natural disaster preparedness according to their respective effects. More specifically, the increase in SMEs and entrepreneurship capital resources as well as the simultaneous decrease in labor will have a direct effect on increasing the level of preparedness for natural disasters.

\section{The Influence of Capital Resources and Entrepreneurship on Natural Disaster Preparedness with Manpower as an Intermediate Variable}

The influence of SMEs capital resources and entrepreneurship on natural disaster preparedness through the SMEs workforce as an intermediate variable is divided into two. First, the influence of indirect variables through intermediate variables and the second, the total effect of direct and indirect effects through intermediate variables.

The indirect effect of SMEs capital resources through labor based on table 4.4 is -0.01 . This shows that the increase in SMEs capital which is intended for workers will actually reduce the level of preparedness for natural disasters. So that the total effect of SMEs Scapital on natural disaster preparedness is 0.06. This illustrates that the effect of SMEs capital on natural disaster preparedness will have a positive effect, which means an increase in SMEs capital resources will also increase the level of natural disaster preparedness.

The indirect effect of entrepreneurial resources through labor based on table 4.8 is 0.01 . This means that an increase in labor-related measures of entrepreneurship will also increase the level of natural disaster preparedness. So that the total influence of SMEs capital on natural disaster preparedness is 0.35 . This explains that the influence of entrepreneurship on natural disaster preparedness will have a positive effect, which means an increase in entrepreneurship will also increase the level of natural disaster preparedness, either directly or indirectly.

\section{CONCLUSION}

Based on the results of research and analysis that has been done, it can be concluded several things as follows:

1. One of the variables that affect the preparedness of natural disasters based on the variable SMEs capital. The direct influence of these resources on disaster preparedness is higher than the indirect effect through the labor variable. The direct influence of SMEs capital on disaster preparedness is 0.07 . This shows that every increase in the variable capital resources of SMEs will also increase the level of preparedness for natural disasters directly.

2. The influence of the SMEs workforce variable on natural disaster preparedness is -0.03 . This shows that every increase in the SMEs workforce variable will actually reduce the level of preparedness for natural disasters. In addition, the SMES workforce variable also acts as an intermediate variable in influencing the indirect effect of the SMES capital resource variable and the entrepreneurial variable.

3. The entrepreneurial resource variables of SMEs directly or indirectly affect the preparedness of natural disasters. The direct effect of entrepreneurial resource variables on disaster preparedness is 0.35 . This value is positive, which means that every increase in the entrepreneurial variable will also have an impact on increasing the level of natural disaster preparedness in SMEs.

4. The variable of information technology resources is not significant in influencing natural disaster preparedness either directly or indirectly through the SMEs workforce variable, so the magnitude of the influence on the model cannot be calculated.

5. The existence of SMEs resources on natural disaster preparedness shows the total direct influence between the variables of SMEs capital resources, SMESworkforce resources and entrepreneurship on natural disaster preparedness. Based on the results of this study, it was found that the number of direct 
effects simultaneously was 0.38 . This shows that simultaneously significant SMEs resources will have a positive effect on increasing natural disaster preparedness. It is clear that the increase in SMEs and entrepreneurship capital resources as well as the simultaneous decrease in labor will have a direct effect and can increase the level of preparedness for natural disasters.

6. The indirect effect of SMEs capital through labor is 0.01. This shows that the increase in SMEScapital that is intended for workers will actually reduce the level of natural disaster preparedness, so that the total effect of SMEs capital on natural disaster preparedness is reduced to 0.06 . The effect of 0.06 is positive. Meanwhile, the indirect effect of entrepreneurial resources through the workforce is 0.01 , which means that an increase in the size of entrepreneurship related to labor will also increase the level of natural disaster preparedness, so that the total effect of SMEs capital on natural disaster preparedness is 0.35 . This explains that the influence of entrepreneurship on natural disaster preparedness will have a positive effect, which means an increase in entrepreneurship will also increase the level of natural disaster preparedness, either directly or indirectly.

7. From the calculation of the response to natural disaster preparedness which has been grouped into four score intervals, then as many as $17.31 \%$ of respondents in the three areas that became the object of the study were declared "less prepared" to face natural disasters, $60.90 \%$ "somewhat ready" and 23 , $8 \%$ are "ready" while none of the respondents are "very prepared" for natural disasters. As many as $60.90 \%$ of respondents in the moderately prepared category can be understood considering that the post disaster they have experienced has become an experience for SMEs so that they can prepare as early as possible to face natural disasters.

8. This research is expected to help the government or stakeholders improve the resilience of natural disasters in disaster-prone areas, particularly preparing the strength of small industries in facing disasters by optimizing the utilization of the resources used. In addition, it also provides scientific contributions to Economics, especially in the Economics literature with theoretical and empirical approaches.

\section{RECOMMENDATION}

In contrast to the findings of previous studies that the labor variable is a very strong predictor variable (Drabek in Dahlhamer \& D'souza, 1995) but in this study it was found that the value of the labor variable was significantly minus. Therefore, if you want to improve natural disaster preparedness at the Food Industry Branch SMEs in Central Sulawesi Province, especially in the Palu Bay Area, the focus of attention is not on the Labor Variables but on the Management Variables, namely by conducting trainings to improve managerial quality. in SMEs both related to business management and disaster management.

\section{BIBLIOGRAPHY}

[1] Badoc-Gonzales, B.P., Mandigma, M.B.S., Tan, J.J., 2021. Resilience and sustainability interventions in selected Post-Haiyan Philippines: MSMEs perspective. Int. J. Disaster Risk Reduct. 57, 102162. https://doi.org/10.1016/j.ijdrr.2021.102162

[2] Chaudhuri, A., Subramanian, N., Dora, M., 2022. Circular economy and digital capabilities of SMEs for providing value to customers: Combined resource-based view and ambidexterity perspective. J. Bus. Res. 142, 32-44. https://doi.org/10.1016/j.jbusres.2021.12.039

[3] Cooper, A.C., Bùi, H.T.T., Nguyễn, L.T., Nguyễn, P.K., Nguyễn, T.H.T., Phan, D.P.N., 2021. Deaf-led organizations and disaster communication in Việt Nam: Interdisciplinary insights for disability inclusive disaster risk reduction planning. Int. J. Disaster Risk Reduct. 65, 102559. https://doi.org/10.1016/j.ijdrr.2021.102559

[4] Dahlhamer, J. M., \& D'souza, M. J. (1995). Determinants of business disaster preparedness in two u.s. Metropolitan areas.

[5] De Simone, M., Callea, L., Fajilla, G., 2022. Surveys and inferential statistics to analyze contextual and personal factors influencing domestic hot water systems and usage profiles in residential buildings of Southern Italy. Energy Build. 255, 111660. https://doi.org/10.1016/j.enbuild.2021.111660

[6] Estensoro, M., Larrea, M., Müller, J.M., Sisti, E., 2021. A resource-based view on SMEs regarding the transition to more sophisticated stages of industry 4.0. Eur. Manag. J. S0263237321001444. https://doi.org/10.1016/j.emj.2021.10.001

[7] Han, P., Yu, H., Yu, X., 2021. A sloshing induced Tsunami: 2018 Palu Bay event. Appl. Ocean Res. 117, 102915. https://doi.org/10.1016/j.apor.2021.102915

[8] Hasan, Md.K., Younos, T.B., Farid, Z.I., 2021. Nurses' knowledge, skills and preparedness for disaster management of a Megapolis: Implications for nursing disaster education. Nurse Educ. $\quad$ Today $107,122$. https://doi.org/10.1016/j.nedt.2021.105122

[9] Hossain, M.R., Akhter, F., Sultana, M.M., 2022. SMEs in Covid19 Crisis and Combating strategies: A Systematic Literature Review (SLR) and A Case from Emerging Economy. Oper. Res. Perspect. 100222. https://doi.org/10.1016/j.orp.2022.100222

[10] J.M., N., 1996. The Social Impacts of Physical Processes: How do we Manage What We Can't Control? Preliminar.

[11] Karunarathne, A.Y., Gress, D.R., 2022. The role of organizational networks in ameliorating flood disaster impacts: A case study of flood inundated rural and urban areas in Sri Lanka. Int. J. Disaster Risk Reduct. 102819. https://doi.org/10.1016/j.ijdrr.2022.102819

[12] Kumar, A., Mishra, S., Singh, S.S., Singh, K., Biswas, B., 2020. Link prediction in complex networks based on Significance of Higher-Order Path Index (SHOPI). Phys. Stat. Mech. Its Appl. 545, 123790. https://doi.org/10.1016/j.physa.2019.123790

[13] Liu, Y., Shen, Y., Cheng, C., Yuan, W., Gao, H., Guo, P., 2022. Analysis of the influence paths of land use and landscape pattern on organic matter decomposition in river ecosystems: Focusing on microbial groups. Sci. Total Environ. 817, 152999. https://doi.org/10.1016/j.scitotenv.2022.152999

[14] Park, E.S., Fitzpatrick, K., Das, S., Avelar, R., 2021. Exploration of the relationship among roadway characteristics, operating speed, and crashes for city streets using path analysis. Accid. Anal. Prev. 150, 105896. https://doi.org/10.1016/j.aap.2020.105896

[15] Qu, X., Lee, L., Yang, C., 2021. Estimation of a SAR model with endogenous spatial weights constructed by bilateral variables. J. Econom. 221, 180-197. https://doi.org/10.1016/j.jeconom.2020.05.011

[16] Roberts, F., Archer, F., Spencer, C., 2021. The potential role of nonprofit organisations in building community resilience to 
disasters in the context of Victoria, Australia. Int. J. Disaster Risk Reduct. 65, 102530. https://doi.org/10.1016/j.ijdrr.2021.102530

[17] Shah, A.A., Shaw, R., Ye, J., Abid, M., Amir, S.M., Kanak Pervez, A.K.M., Naz, S., 2019. Current capacities, preparedness and needs of local institutions in dealing with disaster risk reduction in Khyber Pakhtunkhwa, Pakistan. Int. J. Disaster Risk Reduct. 34, 165-172. https://doi.org/10.1016/j.ijdrr.2018.11.014

[18] Suliyanto. (2011). Ekonometrika Terapan: Teori dan Aplikasi dengan SPSS. Penerbit Andi, Yogyakarta.

[19] Walker, J., Hansen, C.H., Martin, P., Symeonides, S., Ramessur, R., Murray, G., Sharpe, M., 2014. Prevalence, associations, and adequacy of treatment of major depression in patients with cancer: a cross-sectional analysis of routinely collected clinical data. Lancet Psychiatry 1, 343-350. https://doi.org/10.1016/S22150366(14)70313-X

[20] Zhao, B., 2021. Landslides triggered by the $2018 \mathrm{Mw} 7.5$ Palu supershear earthquake in Indonesia. Eng. Geol. 294, 106406. https://doi.org/10.1016/j.enggeo.2021.106406

[21] Zide, O., Jokonya, O., 2022. Factors affecting the adoption of Data Management as a Service (DMaaS) in Small and Medium Enterprises (SMEs). Procedia Comput. Sci. 196, 340-347. https://doi.org/10.1016/j.procs.2021.12.022 